\title{
Results of antero-lateral cordotomy for pain in cancer
}

\author{
P. W. NATHAN ${ }^{1}$ \\ From the National Hospital for Nervous Diseases, Queen Square, London
}

In this paper the effects and the practical results of antero-lateral cordotomy are reported. These results provide a guide to prognosis for those recommending the operation and material for comparison with other methods of treating intractable pain, although no comparison is made here between this and other methods. The anatomical aspects of our findings are not given in detail here.

The series of patients presented in this paper has been collected over the past 15 years. In all the patients cancer was the cause of the intractable pain. Neurosurgery was resorted to only when it was clear that in reasonable doses analgesic drugs would not control the pain. All patients had previously had as much radiotherapy for the cancer as was considered advisable. The majority of the patients were observed daily and they were investigated in considerable detail before and after the cordotomies; the main purpose of the investigation was to study various aspects of the anatomy and physiology of the spinal cord in man.

Sixty-eight of the 114 operations were performed by Mr. Wylie McKissock; the other operations were performed by 15 other neurosurgeons in this country. All the patients whose cases are reported are now dead. The period of survival after the cordotomy was six months or more in 18 patients; in three patients it was less than a week; in all others the duration of survival falls between a week and six months.

The number of patients and operations are shown in Table I. One patient had two bilateral cordotomies and one patient had a unilateral cordotomy followed by a bilateral cordotomy. Seven patients had two unilateral cordotomies, first on one side and then on the other; the interval between the two

\section{TABLE I}

NUMBER OF PATIENTS AND OF OPERATIONS

Total number of patients . . . . . . . . . . . . . . . 104

Total number of cordotomies. . . . . . . . . 114

Bilateral operations..........40 on 39 patients Unilateral operations..........74 on 66 patients

${ }^{1}$ Member external scientific staff, Medical Research Council. operations was two months or less. One patient had two unilateral cordotomies, both on the same side.

The numbers of patients and the kinds of neoplasm are listed in Table II.

TABLE II

NUMBERS OF PATIENTS AND KINDS OF NEOPLASM

Kinds of Neoplasm

Number of Patients

Carcinoma uteri

Carcinoma of colon and rectum

Carcinoma bronchi

Carcinoma vesicae

Chondrosarcoma of the innominate bone

Carcinoma mammae

Melanoma

Carcinoma: primary never found

Epithelioma ani

Carcinoma of pancreas

Carcinoma prostatae

Carcinoma vaginae

Chordoma

Sarcoma

Total

35
24
18
7
5
4
3
2
1
1
1
1
1
1
104

RESULTS

RELIEF OF PAIN The amount of relief from pain attained by the operations is shown in Table III. The number of operations shown in this Table is 111 and not 114 , as three patients having a unilateral operation died too soon after the operation for a final state of relief of pain to be satisfactorily assessed. It should be made clear at the outset that what is shown here is the relief, or the failure of relief, of pain; the Table is not equivalent to a judgment of

TABLE III

RELIEF OF PAIN

\begin{tabular}{lccc}
$\begin{array}{l}\text { Effect of Cordotomy } \\
\text { on Pain }\end{array}$ & $\begin{array}{l}\text { Bilateral } \\
\text { Operation }\end{array}$ & $\begin{array}{c}\text { Unilateral } \\
\text { Operation }\end{array}$ & Total \\
\hline Pain totally relieved & 20 & 38 & $58(52 \%)$ \\
Pain partially relieved & 12 & 16 & $28(25 \%)$ \\
Pain slightly relieved & 7 & 10 & $17(16 \%)$ \\
Pain unaltered & 1 & 7 & $8(7 \%)$ \\
Total number of operations & 40 & 71 & $111(100 \%)$
\end{tabular}


the success or failure of the operation as a way of combatting intractable pain, for into this judgment considerations of factors other than the relief of pain would have to enter.

From Table III, it may be seen that roughly a half of the operations gave complete relief of pain, a quarter gave partial relief, and a quarter failed to give adequate relief.

The assessment of the relief of pain was for the total period between the operation and the patient's death; for the purposes of categorising the relief of pain, only the eventual state was considered; if, for instance, there was complete relief of pain for a period of a month after the operation, followed by a return of pain, then the pain relief was classified as partial, slight, or unaltered, according to the severity of the pain which the patient eventually had.

The categories in Table III of total relief of pain and of unaltered pain are clear and need no further comment. The category of 'pain slightly relieved' indicates that there was some relief of pain though it was not reckoned adequate to have made the operation worthwhile in the opinion of the patient. 'Pain partially relieved' covers the widest extent of pain relief of the categories, embracing all results short of total relief and everything more than a slight relief which did not justify the operation in the eyes of the patient.

From the experience of this series of cases one can conclude that, provided the spino-thalamic tract is totally divided, there is no sort of pain that cannot be stopped by cordotomy. The causes of failure to relieve the pain were anatomical, in the sense that the incision did not cut sufficient fibres of the right part of the spino-thalamic tract. (The term 'spinothalamic tract' is used loosely here, for it is well known that not all fibres concerned with conduction of impulses subserving pain end directly in the thalamus.) That errors in dividing the correct fibres of the spino-thalamic tract may occur can be readily understood, for the anatomy of the tracts of this part of the cord in man has not yet been adequately worked out; in fact, the results reported here form a part of an investigation of the anatomy of the spinothalamic and anatomically related tracts, undertaken to improve the operation of antero-lateral cordotomy. Failure to relieve pain was sometimes due to an inadequate amount of the body being rendered insensitive to pain. In nearly all the patients the cordotomies were performed many segments cranial to the most cranial extent of the cancer, and so the growth rarely spread into parts of the body having a completely normal nervous innervation. But as the growth spread, in some cases it reached regions of the body that had been rendered partially, though not completely, analgesic. Yet so severe is the pain for which a cordotomy is performed $\underset{\mathbb{D}}{Z}$ that anything less than total loss of pain sensibility is inadequate to stop the pain of the cancer being felt. A cordotomy may give rise to some loss of sensibility to pain over an extensive region, perhaps 0 18 segments; yet there may be total loss of sensibility to pain over a much smaller region, perhaps $\stackrel{5}{=}$ nine segments. This region of total loss may be adequate at first to stop the pain of the cancer being. felt, but, as the growth spreads, it may spread into $\vec{F}$ the further nine segments that are partially analgesic, when pain may be felt anew and the opera- $\frac{\mathrm{C}}{\mathrm{C}}$ tion will have failed in its purpose. A further cause of $\frac{\overline{\bar{N}}}{\bar{\rho}}$ failure to stop pain is due to the well-known fact that $\frac{\vec{\sigma}}{\sigma}$ the total region insensitive to pain becomes smaller $\stackrel{\mathbb{Q}}{\circ}$ as time passes; it shrinks in both directions, from $\%$ above downwards and from below upwards. This $\vec{\circ}$ shrinking of the region rendered analgesic is less important in cases of cancer than in cases of intract- $\vec{\omega}$ able pain arising from other, benign disorders. This change in the extent of the parts of the body rendered insentient to pain does not usually start immediately after the operation but takes weeks or months to $\%$ occur, and so, if the patient does not live too long, he may well die before any or much shrinking take्ds place.

The fact that the causes of failure of the operati飠 were anatomical lead to the hope that they a superable and that this operation can be improved. What is needed is more anatomical knowledge, $\frac{\rho}{4}$ particularly of variations in the position of the $\vec{P}$ spino-thalamic tract of the differences in location and extent of the tract at the various segments of $\omega$ the cord, and of the organization of the tract, so that it is known how the fibres subserving each segment of the body are arranged within the tract.

\section{UNAVOIDABLE COMPLICATIONS}

Division of the anterior or the antero-lateral columns $\stackrel{\overline{3}}{3}$ of the spinal cord causes unwanted complications; these are considered here in two groups, unavoidable and occasional. The complications called unavoidable are unavoidable for two reasons: the division of the spino-thalamic tract designed to render certain:parts of the body totally insensitive to painful 3 stimulation inevitably divides other fibres, some being intermingled with others lying superficial to the spino-thalamic fibres; the division of the tract has to be performed several segments cranial to the lesion causing the pain. Thus these complications are $\frac{7}{0}$ in practice unavoidable, although the position of the spino-thalamic tract in the cord might lead one to $N$ suppose that some of the complications might be avoided. The complications called occasional are those that occur only in a proportion of the cases. 


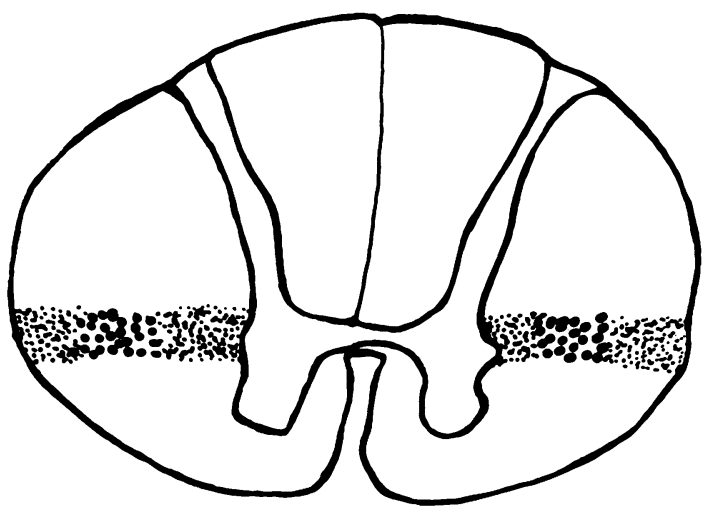

FIG. 1. Diagram showing location of nerve fibres running between the brain and the centres for micturition and defaecation in the sacral segments.

COMPLICATIONS AFFECTING MICTURITION AND DEFAECATION The consequences of a bilateral operation rendering the lower lumbar and sacral segments completely analgesic is to make the functioning of the bladder and rectum automatic. The location of the tracts running between the brain and the centres for micturition and defaecation in the sacral cord has been worked out by Nathan and Smith (1951, 1953, 1958). Their position is shown diagrammatically in Figure 1. The afferent fibres run with the spino-thalamic fibres from the sacral segments of the body. It will be seen from this figure that a bilateral lesion cutting through the spino-thalamic tract in that part where the sacral fibres lie will also involve a large proportion of the fibres of the tracts subserving micturition and defaecation. A superficial cordotomy lesion made here might be expected to cut only the spino-thalamic fibres, and leave most of the descending motor fibres intact. But in fact this rarely happens; this is so because the surgeon knows that he needs to make a fairly deep incision in this part of the cord; a superficial lesion would not cause a long-lasting complete loss of sensibility to pain in the sacral segments, for the arrangement of the fibres of the tract is such that there are fibres from sacral segments lying more anteriorly than the region where the majority lie, as was shown in our previous papers.

The state of micturition and defaecation following bilateral cordotomy is not exactly the same as that occuring after a total division of the spinal cord. The differences between the two clinical conditions are mainly due to the presence of afferent fibres in the posterior columns remaining intact after cordotomy. These posterior column fibres are used in conveying some information about the imminence of micturition and defaecation, information that faeces and urine are passing, and that the acts of micturition and defaecation have finished. They also form the pathway for the vague feeling of abdominal distension that the patient usually acquires and that he learns to associate with a full bladder (Nathan, 1956b). Some patients having automatic micturition and defaecation are able to organize these functions regularly and so satisfactorily that a superficial questioning of the patient may elicit the answer that they are normal. This satisfactory outcome is most likely to occur if the bladder never becomes infected and is never permitted to be distended. Other patients, particularly those worn out by ill health associated with cancer, cannot learn to manage automatic micturition and defaecation, and so they are frequently incontinent.

As the pathways concerned in the encephalic control of micturition and defaecation are bilateral, a unilateral cordotomy causes at most only a temporary disturbance of function, provided the peripheral nerves are intact and are not involved in the neoplasm or fibrosis. That any lack of control will be only temporary constitutes a strong argument favouring a unilateral rather than a bilateral operation, if this operation is otherwise likely to be successful. The bilateral operation, when done in two stages with an interval of one or two months between the two operations, affects micturition and defaecation just as it did when it was carried out in one stage.

COMPLICATIONS AFFECTING SWEATING AND VASOMOTOR TONE Although details of the pathways descending from the brain to the sympathetic centres in the thoracic and upper lumbar segments of the cord have not been fully worked out, it can be stated that a bilateral cordotomy rendering the sacral, lumbar, and most thoracic segments of the body insensitive to painful stimuli stops sweating caudal to the lesion and causes postural hypotension. This latter complication is not usually a source of much discomfort. Often when the patient first gets up after the operation he is liable to feel faint, lightheaded, and to manifest vasoconstriction of the skin and sweating above the lesion; but these manifestations of postural hypotension are temporary. Provided convalescence is gradual, the vasomotor tone adjusts to the postures of sitting, standing, and walking, and the patients who showed this complication were eventually able to be up and about without being aware of anything abnormal related to the tone of the blood vessels. This complication never occurs following a unilateral cordotomy.

COMPLICATIONS AFFECTING RESPIRATION Interference with the descending fibres from the medulla 


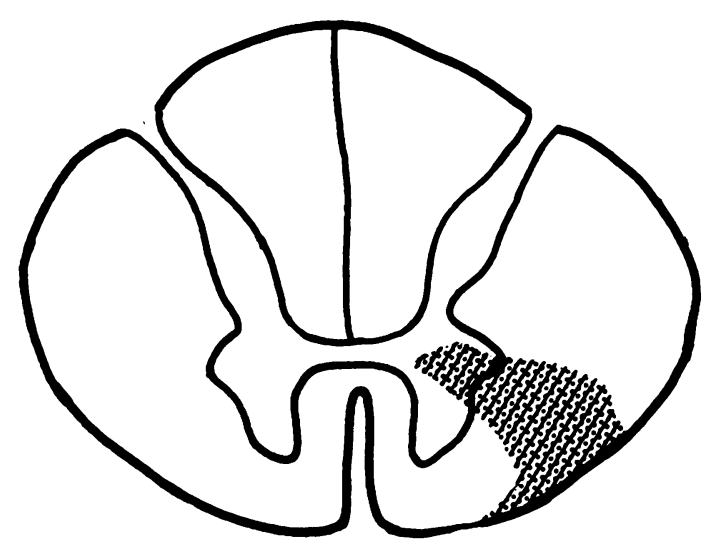

FIG. 2. Diagram showing location of nerve fibres descending from the respiratory centre to the nuclei innervating the diaphragm and intercostal muscles.

oblongata to the motor neurones of the phrenic and intercostal nerves is the main cause of death resulting from the operation when performed in the first three cervical segments. (Evidence concerning the location of these fibres is being published in a later issue.) Their position is shown in Figure 2. It will be seen from this figure that any lesion cranial to the phrenic nuclei that passes through the most anterior part of the lateral column will involve these fibres and will cause paralysis of the ipsilateral respiratory musculature, a paralysis that is only temporary. This alone does not result in death, although it would be liable to do so were a bilateral operation carried out at this level. The matter of respiratory complications of the operation is discussed further under the section on 'occasional complications'.

\section{OCCASIONAL COMPLICATIONS}

COMPLICATIONS AFFECTING THE ALIMENTARY CANAL Distension of the colon and intestinal stasis were seen following bilateral cordotomy to a marked degree in only a few cases. Even when there was marked distension it never constituted a dangerous complication, and always recovered spontaneously within 48 hours of the operation. A slight degree of stasis was commoner, being part of the general discomfort of the first few hours after the operation.

A cordotomy has no permanent effect on the bowel above the anal canal. The presence of a colostomy constitutes no contraindication for performing a cordotomy.

COMPLICATIONS AFFECTING RESPIRATION As has been stated above, a surgical lesion involving the fibres subserving the muscles or respiration, which descend in the most anterior part of the lateral column, will temporarily paralyse ipsilateral res- $\stackrel{\mathbb{D}}{=}$ piratory movements. This paralysis is not necessarily a part of hemiplegia; the paralysis of the respiratory movements can occur without paresis of the limbs. 0

It may happen that the neoplasm causing the pain for which the cordotomy is performed involves $\frac{\text { S }}{5}$ the lung and affects certain of the mechanisms of respiration. The cordotomy has to be carried out on? the opposite side of the chest; if it is successful in $\vec{F}$ removing the pain in the chest it will inevitably cause $\stackrel{?}{?}$ paralysis of the movements of respiration ipsilaterally for a period of hours or days. In addition to the lung $\frac{\bar{\sigma}}{\bar{s}}$ itself, the carcinoma may also involve the phrenic $\frac{\widehat{D}}{\widehat{D}}$

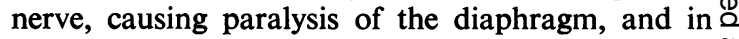
some cases this pathological process may also have involved the recurrent laryngeal nerve. If these $\vec{\circ}$ features of a carcinoma of this part of the body occur together-weakening of coughing, paralysis of the $\vec{\omega}$ diaphragm, and inadequacy of effective respiratory tissue - then the inadequate coughing, the increased secretion of mucus following the operation, the necessity for increased ventilation, all combined with of the addition of paralysis of the respiratory move ments of the opposite side due to the cordotom of may be sufficient to cause death. Further, any of 0 these complications alone, when associated wi even the temporary respiratory paralysis due cordotomy, may be enough to kill the patient.

Of the 20 cases of high cervical cordotomy in thes series, there were serious respiratory complicatious in four; these four patients died as the result of th complication, all within the first week of the operation.

EFFECTS ON MOTILITY OF LOWER LIMBS The disturbance of strength and control of the lower limbs after the bilateral operation varied from none to $\stackrel{\square}{\mathbb{D}}$ paralysis of both limbs. The unilateral operation can $\underset{\vec{F}}{\overrightarrow{2}}$ affect, clinically, only the ipsilateral limb, whereas the bilateral operation may affect one or both lower limbs.

With regard to the terms to be used here, no further comment is needed on 'normal'; 'paralysed' means that the patient cannot or can hardly move the limb and that it buckles up beneath his weight; 'very weak' means that the limb is liable to let him down when he walks and that he needs to walk with the aid of a stick; 'slightly weak' is the term used for any degree of weakness present after the operation that was absent before, and that is not severe enough $\frac{D}{0}$ for the term 'very weak'.

The simplest case to consider first is the effect of a $N$ unilateral cordotomy on the movements of the ipsilateral lower limb. This is shown in Table IV. N It will be seen that of the 59 lower limbs that were 
TABLE IV

STATE OF MOTILITY OF LOWER LIMB IPSILATERAL TO A UNILATERAL CORDOTOMY BEFORE AND AFTER OPERATION

\begin{tabular}{|c|c|c|c|c|c|c|c|}
\hline \multicolumn{4}{|c|}{ Limbs before Operation } & \multicolumn{4}{|c|}{ Limbs after Operation } \\
\hline Normal & Slightly Weak & Very Weak & Paralysed & Normal & Slightly Weak & Very Weak & Paralysed \\
\hline 59 & 3 & & & $41(70 \%)$ & $\begin{array}{c}13(22 \%) \\
2\end{array}$ & $\frac{2}{1}(3 \%)$ & $3(5 \%)$ \\
\hline
\end{tabular}

TABLE V

STATE OF MOTILITY OF LOWER LIMB IPSILATERAL TO EACH INCISION OF A BILATERAL CORDOTOMY BEFORE AND AFTER OPERATION

Limbs before Operation

\begin{tabular}{|c|c|c|c|c|c|c|c|}
\hline Normal & Slightly Weak & Very Weak & Paralysed & Normal & Slightly Weak & Very Weak & Paralysed \\
\hline 67 & 15 & 5 & 1 & $37(55 \%)$ & $\begin{array}{r}19(28 \%) \\
6(40 \%)\end{array}$ & $\begin{array}{l}7(11 \%) \\
8(53 \%) \\
4\end{array}$ & $\begin{array}{l}4(6 \%) \\
1(7 \%) \\
1 \\
1\end{array}$ \\
\hline
\end{tabular}

TABLE VI

RISK TO MOTILITY OF NORMAL OR SLIGHTLY WEAK LOWER LIMBS OF BILATERAL AND UNILATERAL CORDOTOMY

\begin{tabular}{cccc} 
No. of Cases & Type of Operation & $\begin{array}{l}\text { Operation Caused No or } \\
\text { Slight Damage to Motility } \\
\text { of Lower Limb }\end{array}$ & $\begin{array}{l}\text { Operation Caused Severe } \\
\text { Damage to Motility of } \\
\text { Lower Limb }\end{array}$ \\
\hline 41 & Bilateral & $62(76 \%)$ & $\begin{array}{l}\text { Total Number of } \\
\text { Limbs at Risk }\end{array}$ \\
62 & Unilateral & $56(90 \%)$ & $6(24 \%)$ \\
$6(10 \%)$
\end{tabular}

normal before the operation, 41 were unaffected by the operation, 13 were slightly weakened, two were much weakened, and three were paralysed. Three lower limbs were slightly weak before the operation, two were unaffected, and one was rendered very weak.

To consider the effect of a bilateral cordotomy (whether done in one or two stages) on the movements of the lower limbs, the simplest case is to examine the effects of each incision on the ipsilateral lower limb; this is assuming at first that a bilateral cordotomy is the same as two unilateral cordotomies. It is seen from Table $\mathrm{V}$ that of the 67 lower limbs which were normal before the operation, $37(55 \%)$ were unaffected by the operation, $19(28 \%)$ were slightly weakened, seven $(11 \%)$ were severely weakened, and four $(6 \%)$ were paralysed. Of the 15 limbs already slightly weak before the operation, six were unaffected and nine were much weakened. The risk to the motility of the lower limbs from a bilateral cordotomy in this series is thus seen to be considerable. A bilateral cordotomy is more harmful to the motility of each lower limb than a unilateral cordotomy is to the ipsilateral lower limb.

The danger to each lower limb from each type of operation can be more clearly seen from Table VI. There were 82 lower limbs at risk with the bilateral operation and 62 with the unilateral operation; those in which there was gross weakness or paralysis before the operation are not included. Following the bilateral operation, a quarter of the lower limbs were rendered very weak or paralysed, and following the unilateral operation a tenth of the lower limbs were rendered very weak or paralysed. Thus the bilateral operation caused severe damage to the function of a lower limb two and a half times as often as the unilateral operation. The risk to each ipsilateral lower limb is seen to be far greater with a bilateral than with a unilateral operation. Of 44 bilateral operations, 23 patients came to the operation with no disorder of motility of the lower limbs; 13 had no disorder after the operation, the other 10 had acquired some disorder of motility from the operation.

The fact that each lower limb runs a greater risk from a bilateral cordotomy than does the one limb from a unilateral cordotomy indicates that the incision on each side of the cord in fact affects the motility of both lower limbs. This effect cannot be seen clinically when a unilateral operation is carried out, but it comes to light from these figures.

It has been suggested by some neurosurgeons that if a bilateral cordotomy is performed in two stages with an interval of weeks or months between 
the two unilateral operations, the complications affecting micturition, defaecation, and the lower limbs will be less. In this series, there were seven patients in whom the operation was performed in two stages. All these seven patients had normal motility of both lower limbs before the operation; after the second operation four lower limbs were paralysed, three were severely affected, five were slightly affected, and only two were still normal. In fact these patients, in this series, fared worse than those in whom the bilateral operation was carried out in one stage. It thus comes out clearly that a bilateral operation done in two stages is certainly not less dangerous than the operation done in one stage.

A further fact regarding the motility of the lower limbs comes to light from carrying out this operation in two stages. If the first operation damages the motility of the ipsilateral limb, say the right, a certain amount of recovery ensues, starting within days or weeks. After the second operation on the opposite side of the cord, in this case on the left side, all the recovery of function is immediately removed. This indicates that the recovery following the original lesion was due to use being made of the pathways of the contralateral side of the cord.

If part of the price that the patient has to pay for the relief of pain is to have his lower limbs weakened, it is important to consider the relation between the amount of relief of pain obtained and the degree of weakness of the lower limbs in more detail.

\section{TABLE VII}

EFFECT OF UNILATERAL CORDOTOMY ON PAIN AND ON MOTILITY OF IPSILATERAL LOWER LIMB

\begin{tabular}{|c|c|c|c|c|c|}
\hline \multirow{2}{*}{$\begin{array}{l}\text { State of Lower } \\
\text { Limbs after } \\
\text { Operation }\end{array}$} & \multicolumn{4}{|c|}{ State of Relief of Pain } & \multirow[t]{2}{*}{ Total } \\
\hline & Total & Partial & Slight & None & \\
\hline $\begin{array}{l}41 \text { normal } \\
15 \text { slightly weak } \\
3 \text { very weak } \\
3 \text { paralysed }\end{array}$ & $\begin{array}{r}17 \\
11 \\
3 \\
2\end{array}$ & $\begin{array}{r}10 \\
3 \\
0 \\
1\end{array}$ & $\begin{array}{l}9 \\
1 \\
0 \\
0\end{array}$ & $\begin{array}{l}5 \\
0 \\
0 \\
0\end{array}$ & $\begin{array}{r}41 \\
15 \\
3 \\
3\end{array}$ \\
\hline Total 62 & 33 & 14 & 10 & 5 & 62 \\
\hline
\end{tabular}

TABLE VIII

EFFECT OF BILATERAL CORDOTOMY ON PAIN AND ON MOTILITY OF LOWER LIMBS

\begin{tabular}{lccccc}
$\begin{array}{l}\text { State of Lower } \\
\text { Limbs after } \\
\text { Operation }\end{array}$ & \multicolumn{2}{l}{ State of } & Relief of Pain & Total \\
\cline { 2 - 5 } & Total & Partial & Slight & None & \\
\hline 37 normal & 20 & 10 & 7 & 0 & 37 \\
25 slightly weak & 11 & 9 & 3 & 2 & 25 \\
19 very weak & 11 & 5 & 2 & 1 & 19 \\
7 paralysed & 7 & 0 & 0 & 0 & 7 \\
Total 88 & 49 & 24 & 12 & 3 & 88
\end{tabular}

CORRELATION OF RELIEF OF PAIN AND STATE OFD LOWER LIMBS The correlation between the state of the ipsilateral lower limb after a unilateral cordotomy and the amount of relief of pain obtained is shown in Table VII, and between the state of each ${ }_{\mathcal{C}}$ lower limb after a bilateral cordotomy and the relief of pain obtained in Table VIII. The figures shown in Table VII include operations performed in the cervical cord; these will also be considered:separately in Table IX.

If one considers first the unilateral operation, oneo can see from Table VII that a half of the patients듬 who obtained total relief of pain had no weakness $\overline{\bar{T}}$ of the lower limbs (17 of 33); a third (11 of 33) had $\overparen{Q}$ one lower limb rendered slightly weak. If one considers the 47 patients who obtained total or partial ${ }^{\text {s }}$ relief of the pain, one sees that six $(13 \%)$ were left $\overrightarrow{0}$ with a very weak or paralysed lower limb. Of the 15 who obtained only slight or no relief from the operation, none were left with very weak or paralysed $\overline{7}$ lower limbs and 14 did not have the motility of ato lower limb affected by the operation. Thus it appears that the more likely the operation is to be successful in relieving the pain, the more likely it $j \omega$ to disturb the motility of the ipsilateral lower lim\$. This fact is probably due to the incision made in the cord being large in the case of successful operations and small when the operation is a failure.

If one considers the bilateral operation, it will bec seen from Table VIII that two-fifths of the patiens who obtained total relief of pain had no weakn $\overrightarrow{0}$ of the lower limbs (20 of 49); this figure becomes three-fifths if we include those who were left with slight weakness of a lower limb; thus two-fifths of those who obtained complete relief of pain were left with a lower limb very weak or paralysed. To correlate further the damage to motility of a limb $\frac{\mathbb{Q}}{\mathbb{Q}}$ and the relief of the pain, it is necessary to consider $\varrho$ each patient as consisting of two halves and to $\overrightarrow{0}$ introduce the unusual term of 'hemi-patient'. If 3 one considers the 73 hemi-patients in whom there? was total or partial relief of pain after the operation, $23(31 \%)$ lower limbs were rendered very weak or paralysed. Of the 15 hemi-patients in whom there? was only slight or no relief of pain, no limbs were $\frac{0}{7}$ paralysed, three were left very weak, five were slightly weakened, and seven were unaffected. It is 0 clear from Tables VII and VIII that the successful 2 bilateral operation causes more damage to the ipsi-음 lateral lower limbs than does the successful uni- $\supset$ lateral operation ( $31 \%$ to $13 \%$ ).

EFFECTS ON MOTILITY OF UPPER LIMBS Twenty. operations in the cervical cord cranial to the sixth ${ }_{0}$ cervical segment were carried out in 20 patients; N one patient had a bilateral operation. Operations in 
these segments could potentially damage the motility of the upper limbs as well as that of the lower limbs.

It was found that the upper limb contralateral to the incision was never affected, as judged clinically, by the operation. Of the 21 ipsilateral upper limbs at risk, 16 were unaffected, two were slightly affected, two were severely affected, and one was paralysed. This cervical cordotomy affected the ipsilateral lower limb in four cases: in three severely, in one slightly. (The figures with regard to the lower limbs are included in the previous section on damage to the motility of the lower limbs.) In only one case did the operation affect the ipsilateral lower limb and not the ipsilateral upper limbs.) Thus, in four cases, the cervical cordotomy caused a hemiparesis; in two this was severe, in two it was slight.

The relation between the amount of relief of pain derived from the operation performed on the cervical cord and the degree of weakness of the ipsilateral upper limb can be seen from Table IX. Of

\section{TABLE IX}

EFFECT OF CERVICAL CORDOTOMY ON PAIN AND MOTILITY OF IPSILATERAL UPPER LIMB

\begin{tabular}{|c|c|c|c|c|c|}
\hline \multirow{2}{*}{$\begin{array}{l}\text { State of Upper } \\
\text { Limb after } \\
\text { Operation }\end{array}$} & \multicolumn{4}{|c|}{ State of Relief of Pain } & \multirow[t]{2}{*}{ Tota } \\
\hline & Total & Partial & Slight & None & \\
\hline 15 normal & 6 & 4 & 3 & 2 & 15 \\
\hline 3 slightly weak & 1 & 1 & 1 & 0 & 3 \\
\hline 2 very weak & 2 & 0 & 0 & $\mathbf{0}$ & 2 \\
\hline 1 paralysed & 1 & $\mathbf{0}$ & $\mathbf{0}$ & $\mathbf{0}$ & 1 \\
\hline Total : 21 & 10 & 5 & 4 & 2 & 21 \\
\hline
\end{tabular}

the 10 patients who obtained complete relief of pain, three were left with much weakness of an upper limb. Operations which gave partial, slight, or no relief did not severely affect the motility of the upper limb.

SENSORY COMPLICATIONS There are two kinds of sensory disturbance that affect the success of cordotomy. The results of the operation may be marred by unpleasant dysaesthesiae; the pain may no longer be felt in the original place but be referred elsewhere. This phenomenon has been investigated and discussed earlier (Nathan, 1956a, 1959); it will be discussed briefly here, as it affects the results of cordotomy.

Reference of pain After the unilateral operation, the patient may experience pain in a part of the body where it had not been felt before. In those cases in which this occurs, it can be shown that painful, cold, or certain other sorts of stimuli applied to the part of the body rendered analgesic are referred to parts of the body that still have a normal or almost normal innervation. The new pain, occurring immediately after the division of the spino-thalamic tract or developing over the next few weeks, is apparently due to a reference of the original pain; impulses arising from the neoplasm are blocked in the opposite spino-thalamic tract, but they reach the neurological substratum of consciousness by other pathways. They must be conducted via chains of neurones, and it is postulated that these chains are in the posterior half of the spinal cord and they might well be neurones connecting the cells of origin of the spino-thalamic tract in the posterior horns. Why this conduction of impulses via short chains of neurones should occur in some cases and not in others is unknown; if there were always conduction of impulses in this way, then the operation of cutting the spino-thalamic tract would never be successful.

The reference of pain has been seen following division of the spino-thalamic tract at any level. It is of interest to note that it has been seen also in a case of thrombosis of the posterior inferior cerebellar artery, where the spino-thalamic tract is divided by the ischaemic process high in the medulla oblongata.

The commonest pattern of the reference of the original pain after unilateral cordotomy is for the pain to be referred to the same place on the opposite side of the body as that in which it had been felt before the operation. Occasionally this pain has been so severe that a further cordotomy on the opposite side of the body had to be carried out. This second cordotomy on the opposite spinothalamic tract has then removed the referred pain and the tenderness by rendering the region to which the pain was referred insensitive to pain. Another pattern of reference of pain is for it to be referred to a region of the body cranial to the part of the body rendered analgesic; it is referred to a part of the body that is normally algesic or partially algesic, being situated immediately cranial to the region rendered analgesic. This form of reference is one of the causes of the pain and tenderness situated immediately cranial to the region of total loss of pain sensibility that sometimes persists for weeks or months after the operation.

In 61 patients who had a unilateral cordotomy (five were not seen often enough to assess this), the pain was referred after the operation in 17 patients. It occurred after one bilateral cordotomy; this was a case in which the operation was carried out in two stages with two months between the two unilateral operations; there was reference of the pain following the first operation, and in this case it persisted after the second operation, as the region 
to which the pain was referred remained cranial to the region that had been rendered analgesic. In other patients in whom a second operation was performed, the pain was no longer referred, as the region to which it had been referred after the first cordotomy was then within the region that had been made analgesic.

Unpleasant dysaesthesiae Unpleasant dysaesthesiae occurred in six out of 74 unilateral operations and in one out of 39 bilateral operations. It is sometimes said that these dysaethesiae are most likely to follow the high cervical operation; in this series they occurred only following cordotomies carried out in the thoracic cord, though it must be remembered that the great majority of the cordotomies reported here were thoracic ones. Although such dysaesthesiae may be very unpleasant and most severe, the patients do not describe them as painful. They are described as hot, burning, a feeling of soreness inside, 'the limb feels solid'; one patient said that everything she lay on felt knobbly, hard, and big. This sensation is always different in character from the original pain, although it may have roughly the same distribution. The dysaesthesiae were usually felt in the entire region of the body rendered analgesic; they were sometimes increased by noxious stimulation; and they were usually more severe in that part of the body in which there was pain before the cordotomy and in which the cancer continued to be a constant noxious stimulus. That they depend on an input from the peripheral nerves and do not arise at the level of the cordotomy incision or further cranially is shown by the fact that they are removed by a spinal anaesthetic that covers the region in which they occur.

After a cordotomy, and particularly a bilateral one, pain and tenderness may be experienced at the zone where the normally innervated region adjoins the region in which there is loss of sensibility to pain. This state is not prevented by cutting a posterior root at the level of the cordotomy incision. This pain and tenderness rarely lasts for more than a few weeks after the operation. It is always far less severe than the pain for which the operation was originally performed and does not form a contraindication for performing the operation.

\section{DISCUSSION}

Series of cases of cordotomy published before 1955 were reviewed by White and Sweet (1955). With regard to the relief of pain, White and Sweet found in 100 of their own cordotomies that, when the results were assessed two or more months after the operation, effective relief of the original pain was obtained in $63 \%$, partial relief in $18 \%$, and a failure to relieve pain in $19 \%$. These figures are similar to those reported here; for some of our patients with partial relief might be classified as effective relief, and some, though not all, with pain slightly relieved might be classified as failures.

It will be realized that the results of one operation are not really fully comparable to those of another. An operation that stops all the pain for one month in a patient who lives only a month might well not have been successful in stopping the pain if the patient had lived a further six months. Thus the success of the operation is related, among other factors, to the prognosis and the duration of survival of the patient. Further, mere statistics do not give a real idea of the effectiveness of the operation. Patients have been seen who were in sheer agony and this was completely relieved for the rest of their lives. It is unlikely that such severe pain could be so effectively removed by any other means.

For the patient the most important question is whether he gets relief of pain or not. The main disadvantages of the operation carried out for the relief of pain are the disturbances in conscious control of micturition and defaecation, and weaknesș of one or both lower limbs. These are severe como 어 plications; whether it is worth incurring such risk\$ depends on the severity of the pain, on the expectation of life, and on the fact that simpler methods combatting pain have been tried and failed.

The figures reported here of the effect of the operation on the power and the control of the lower. limbs are far more unfavourable than those of a others who have reported the results of cordotomy. It should be stressed that the results reported here are those of many surgeons, and that they are therefore probably representative of the results obtained in general.

The only way that I can explain this difference is that different criteria have been used by other authors and by myself. In this series most patients were examined in considerable detail, films of the movements of the lower limbs being made before and after the operation. These patients formed a part of an investigation of certain aspects of the physiology and anatomy of the spinal cord. Any abnormality was noted and recorded. Any patient in whom the lower limbs were at all weak after operation was therefore placed in the category of 'slightly weak'. Such patients might well have been placed in the category of 'normal' in series reported by the surgeon who himself performed the operation. If the patients here reported as 'slightly weak' had been placed in the category of 'normal', then $83 \%$ N of lower limbs would have been normal following bilateral cordotomy and $92 \%$ following unilateral cordotomy. 
Many neurosurgeons have the impression that the complications are less severe if the bilateral operation is carried out in two stages with an interval of a few weeks between the two operations. This impression was not supported by the results reported above.

It is in fact arbitrary to assess the results of others and to make meaningful comparisons. To mention one point among many; in this series I have stated whether there was any involvement of the power of the lower limb or limbs before the operation; this was not done by those who have reported other results. Yet this is important not only because it gives a true account of the state of the patients' motility before the operation; for peripheral weakness and central paresis summate, and an operation that might cause no ill effects to the lower limb where the lower limb has a full and normal peripheral innervation may tip the balance of a limb in which there is some invasion by cancer of the sciatic nerve, rendering a slightly weak limb completely paralysed.

The results regarding motility presented here may be compared with those published by Babtchine (1936), Grant (1941), Stookey (1943), and White and Sweet (1955). Babtchine found in unilateral cordotomies that there is usually ipsilateral hypotonia lasting for 15 days of the lower limb. Grant (1941) reported motor weakness in nine of 54 bilateral cordotomies and in five of 55 unilateral cordotomies. Stookey (1943) reported that 'motor weakness is a rare complication' of the unilateral or the bilateral operation, and White and Sweet (1955) found 'obvious weakness of the leg on the side of the cordotomy was a cause of complaint after $4 \%$ of our unilateral operations and twice as often after bilateral tractotomy'.

The unilateral operation is liable to fewer complications than the bilateral: disturbances of micturition and defaecation are only temporary; the risk to the power of the lower limb is far less. It is an operation which, when carried out below the fourth cervical segment, is accompanied by few complications but it is not certain that it will stop all pain, as between a quarter and a third of the patients are liable to develop a reference of the original pain to a part of the body where pain can still be felt. This complication, in my opinion, should not make one counsel against a unilateral operation, if it is otherwise indicated, for the new pain on the opposite side is rarely as severe as the old pain and if it also becomes unbearable a second cordotomy can be performed. The decision whether a unilateral or a bilateral cordotomy should be carried out does not depend only on the complications of the operation; the present position and the probable future spread of the neoplasm, and the presence of even slight pain on the side of the body opposite to that where the maximal pain is occurring, these are the main factors that lead the surgeon to decide which type of operation he should perform.

The results of the unilateral and of the bilateral operations are not fully comparable. For almost a third of the unilateral operations were performed on the cervical cord whereas only two patients have been seen who had a bilateral operation at this level. Obviously the complications are different at the different cord levels; it is, for instance, impossible to damage the ability to move the upper limb from operations performed below the first thoracic segment.

The judgment one makes on the total results of the operation is a subjective matter, into which many factors no doubt enter. Leriche (1937), for instance, gave up this operation almost completely after ten years' experience of it. His reasons were the prevalence of girdle pain at the region between that of normal sensibility and that of pain insensitivity, loss of control of micturition with subsequent ascending infection, eventual failure of the operation, usually due to shrinkage of the region rendered totally analgesic. This certainly seems to be an extreme view. In my experience the girdle pain, though in a few cases it has continued for a few months, has never been severe enough to make the patient regret having had the operation. And nowadays infection of the urinary tract can be more satisfactorily treated than it could be in Leriche's time. And finally, when the operation is performed an adequate number of segments cranial to the most cranial extent of the neoplasm and the incision is carried posteriorly just behind the denticulate ligament, the shrinkage of the region rendered analgesic in a patient with an advancing neoplasm is not such a likely occurrence that it should deter the surgeon from performing this operation.

Only the results of the treatment of pain in painful forms of cancer have been considered here. The operation is certainly less valuable as a method of treating severe pain when it is performed for any condition that does not shorten life.

The success or the failure of this operation is not only a matter of relief of pain. Even considered at first merely from the point of view of relief of pain, the success or failure is not a simple thing to assess. If a patient has to undergo an operation for the relief of severe pain and still has any pain left after the operation, then the operation should perhaps be accounted a failure. Any pain that is constant tends to make life miserable. On the other hand, patients have been seen, who before this operation had to be in hospital and on large doses 
of morphine, amidone, or pethidine, and were in bed almost all the time. After the operation their pain could be controlled by mild analgesics, such as aspirin, phenacetin and codein, and they were able to be at home, look after their children, cook, and run their homes.

Although the operation is carried out for the sake of the patient, his judgment of the operation is not the only one to be considered. The patient will consider the relief of pain (the previous severity of which he very soon forgets) as one of the most important factors in his assessment of the operation; the price he had to pay in the form of complications is another factor; the unpleasantness of the first few days after the operation is yet another. But the patient's view cannot be the same as the doctor's who is looking after the patient. For the patient is ignorant of the prognosis and in nearly all cases he does not realize that he has a fatal illness. Further, the patient is ignorant of other methods of combatting intractable pain; complications that may seem to the patient to be insupportable can appear to the doctor as a price that the patient has to pay to be completely freed of pain. All methods, including analgesic drugs, of combating intractable pain have disadvantages; the patient may know only the disadvantages of the method that has been used in his case.

\section{SUMMARY}

The results of the operation of unilateral and bilateral cordotomy for severe pain in patients with cancer are presented and compared with results previously published.

The following results of the 114 operations are presented. Pain was totally relieved in about a half of the cases; good but incomplete relief was obtained in a further quarter. The operation performed on the cervical cord cranial to the phrenic nuclei caused a temporary paralysis of the movements of respiration. The operation in some patients caused dis- turbance of the motility of the lower, and if done in the cervical cord, of the upper limbs. The com-⿳亠丷厂犬 plications were no less severe if the bilateral operation was done in two stages with several weeks' intervato between the stages. There were also complications affecting micturition and defaecation, sweating and vasomotor tone, and sensory complications, in- $\frac{\bar{N}}{\bar{v}}$ cluding reference of the pain into a normally sentient part of the body, and unpleasant dysaesthesiae.

The neurosurgeons who cooperated in this investigation 음 by giving me opportunities to examine their patients $\frac{\bar{\Phi}}{\sqrt{ }}$ before and after the operation and by helping us obtain necropsies of the patients who had been operated upon were Miss Diana Beck, Professor Norman Dott, Mr. Murray Falconer, Mr. Bernard Harries, Mr. Phillip $\vec{\circ}$ Harris, Mr. William Henderson, Mr. Harvey Jackson, $\vec{\overrightarrow{ }}$ Professor Geoffrey Jefferson, Mr. Vance MacDonald, $\vec{\omega}$ Mr. J. E. A. O'Connell, Mr. J. G. Roberts, Mr. Peter Schurr, Mr. Eric Turner, Mr. L. S. Walsh, and Mr. Dickson Wright; I am most grateful to them for their help. I would like to thank also the many pathologists o who helped us by letting us have the post-morten material. I want also to thank Dr. E. A. Carmichael fö w his encouragement and the facilities he provided through out this work. I would like to thank Mr. Wylie McKissoct 을 particularly; he operated on more than a half of these patients, and he helped me in every way throughout the investigation.

\section{REFERENCES}

Babtchine, I. S. (1936). J. Chir. (Paris), 47, 26.

Grant, F. C. (1941). J. Amer. med. Ass., 116, 567.

Leriche, R. (1937). Rev. neurol., 68, 317.

Nathan, P. W. (1956a). J. Neurol. Neurosurg. Psychiat., 19, 88.

- (1956b). Ibid., 19, 101.

- (1959). Proc. roy. Soc. Med., 52, 989.

- (1963). In press.

- and Smith, Marion C. (1951). J. Neurol. Neurosurg. Psychiat. 14, 262.

$-\longrightarrow$ (1953). Ibid., 16, 245.

Stookey, B. (1943). Res. Publ. Ass. nerv. ment. Dis., 23, 416.

White, J. C., and Sweet, W. H. (1955). Pain. Thomas, Springfield Illinois. 